\title{
A ARTE DE AMAR ... E DE FINGIR: UM ENSAIO DISCURSIVO SOBRE O AMOR EM OVÍDIO
}

\author{
CÁSSIO EDUARDO SOARES MIRANDA ${ }^{1}$
}

\author{
Universidade Federal do Piauí - UFPI \\ Programa de Pós-graduação em Saúde e Comunidade \\ Avenida Frei Serafim, 2280 - Teresina, Piauí, CEP 64000-020 \\ cassioeducufpi.edu.br
}

\begin{abstract}
Resumo. Este ensaio tem como objetivo analisar discursivamente a obra $A$ arte de amar, de Ovídio. A partir da noção de visada discursiva (CHARAUDEAU, 2004), pretende-se destacar o uso de estratégias discursivas na obra desse escritor latino, cuja finalidade é a de sustentar a lógica amorosa no jogo das aparências. Pretendemos verificar, com essa análise, se as estratégias utilizadas por Ovídio se aplicam aos jogos amorosos contemporâneos.
\end{abstract}

Palavras-chave. Ovídio; visada discursiva; estratégias; amor.

\begin{abstract}
This essay aims to analyze discursively the work The Art of Loving, by Ovid. From the notion of a discursive perspective (CHARAUDEAU, 2004), it is intended to highlight the use of discursive strategies in the work of this Latin writer, whose purpose is to sustain the logic of love in the game of appearances. We intend to verify, with this analysis, if the strategies used by Ovid apply to contemporary love games.
\end{abstract}

Keywords. Ovid; discursive approach; strategies; love.

\section{INTRODUÇÃO}

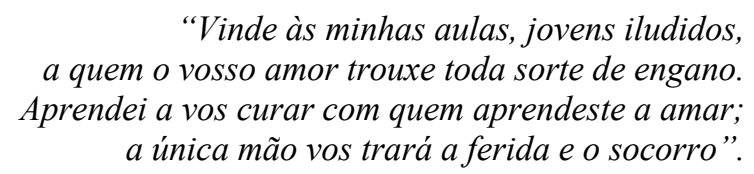

Ovídio.

Como se sabe, o discurso amoroso constitui-se como um dos motores do universo de ficção, inspirando novelas ou séries de televisão, filmes, romances, revistas e todo um conjunto de produtos provenientes da cultura de massas e da indústria cultural. Trata-se do tema mais problematizado na história da ciência, sendo investigado pela psicologia,

\footnotetext{
${ }^{1}$ Psicanalista e professor permanente do Programa de Pós-graduação em Saúde Coletiva da UFPI.
} 
pela filosofia, pela medicina, pela biologia, pela literatura, só para citar alguns. De modo geral, ao se tratar do discurso amoroso e suas principais formas de representação, a construção de uma imagem das relações entre homens e mulheres, seja através da mídia, seja através da literatura, tende a cristalizar posições de homens e mulheres na sociedade, independentemente da época em que foram escritos ou produzidos, semiotizando, dessa forma, a relação entre parceiros, sejam eles do mesmo sexo, sejam eles do sexo oposto.

O estudo do discurso amoroso na literatura e também em revistas denominadas de gênero, parece-nos, tem sido alvo de poucos estudos, sendo que a maior parte das pesquisas em Análise do Discurso de vertente francesa (ADF) são centradas em revistas femininas e principalmente discutem dimensões ideológicas sob o referencial pecheutiano $^{2}$. Desse modo, neste trabalho optamos por realizar um ensaio de análise da obra $A$ arte de amar, de Ovídio, tendo em vista que, a nosso ver, sua obra se constitui como um discurso social capaz de evidenciar o uso de modelos socioculturais e da criação de imaginários sócio-discursivos determinantes em uma dada sociedade. Nota-se também, em tais textos, um acentuado uso de estratégias de sedução, fazendo com que estes aspectos apareçam no processo de semiotização do mundo e também no panorama dos estudos da emoção.

Sendo assim, o presente ensaio tem como finalidade analisar $A$ arte de amar, de Ovídio, levando-se em consideração a noção de visadas discursivas e seus efeitos produzidos, seja na construção do ethos do autor, seja nos efeitos produzidos no leitor.

\section{A VISADA DISCURSIVA OVIDIANA}

Contemporâneo ao Kama Sutra surge, em Roma, A arte de amar, de Ovídio, com evidentes características de poema didático. Como se sabe, em linhas gerais, a denominada poesia didática tem por finalidade ensinar alguma coisa, seja no campo da ciência, das artes, da cultura ou da moral. Com raízes na literatura produzida pelos chamados povos primitivos, ela tinha como alvo facilitar, pelo ritmo e pela rima, a assimilação, a compreensão e a acomodação de dadas verdades (FERNANDES, 2012).

Como uma espécie de um Zeitgeist da época, os escritos ovidianos em muito se assemelham no conteúdo, ao Kama Sutra, ambos podendo ser qualificados como narrativas que ensinam a arte de fingir no amor ${ }^{3}$. O que denominamos de "arte de fingir" refere-se a um conjunto de estratégias e artifícios amorosos utilizados por homens e mulheres para conquistarem seus parceiros/as. O que importava era o estabelecimento de um modo de vida, pelas "elites", fundamentado em uma ética do prazer, em que o amor ficava em segundo plano, pois representava uma espécie de "despossessão". Assim, "fingir no amor" era criar estratégias de conquistas em que se fazia uma aparência de amar, mas que não passava de um jogo de máscaras estabelecido. Em nossa perspectiva,

\footnotetext{
2 Para tanto, basta ver a quantidade de material apresentado em congressos, simpósios, seminários e encontros de Análise do Discurso nos últimos anos para se ter uma ideia de como o discurso sobre a mulher em revistas femininas tem sido tomado como objeto de estudo.

${ }^{3} \mathrm{O}$ Kama sutra e $A$ arte de amar possuem uma grande semelhança discursiva: ambos se utilizam de estratégias semelhantes para o ensino, que são uso de máximas, citações de autoridades, uso de oposições e um tipo de discurso que se assemelha à literatura sapiencial. Podem-se encontrar semelhanças com os escritos de Salomão, o sábio de Israel ou ainda com os sábios essênios, ou ainda com um modo bastante semelhante aos discursos de Jesus Cristo.
} 
sustentamos que temos em Vatsyayana e em Ovídio o estabelecimento de um gênero que se funda no espírito de um tempo e deixa, fenomenologicamente, rastros que podem ser tomados não como regras, mas como princípios norteadores de leitura. Segundo Charaudeau (2004), um gênero se funda também em um aspecto da ancoragem social e se une a uma multiplicidade de práticas sociais que se enraízam em uma dada sociedade. Tais práticas podem ter referências reais que garantirão a troca verbal e, ainda, um campo simbólico em que as relações sociais são estruturadas. Mesmo que uma concepção de ancoragem social apresente problemas, é importante ressaltar que o sujeito falante só se constitui enquanto um sujeito inscrito nas trocas verbais a partir das referências sígneas nas quais ele se inscreve. Assim, tanto em Vatsyayana quanto em Ovídio, embora distantes do espaço, tem-se uma memória dos discursos "na qual são construídos saberes de conhecimento e de crença sobre o mundo" (CHARAUDEAU, 2004, p. 19). São estes discursos que garantem o surgimento de uma representação e criam as comunidades discursivas.

Sendo assim, na comunidade discursiva do ensino da arte de amar, pode-se dizer também que existe a arte de fingir enquanto um componente do jogo da sedução. Se o Kama Sutra ensina as regras do amor e do desejo, ele ensina também o fingir como uma estratégia para conquistar o objeto amado ${ }^{4}$. Se Ovídio ensina a Arte de Amar, ele ensina também a arte de fingir ${ }^{5}$. É oportuno salientar que o relacionamento entre os amantes se torna um "serviço amoroso" semelhante ao serviço militar em que, uma vez tendo vencido uma batalha, o soldado recebe a recompensa pelo seu esforço e por sua luta. Segundo Ovídio, a recompensa como fruto da batalha só advém quando o amante domina a arte de amar e aquele que não a conhece deve aprender: "Se alguém deste povo desconhece a arte de amar, que leia este poema e, uma vez por ele instruído, ame” (2007, p. 23). Para o escritor latino, qualquer pessoa que se guiar corretamente por suas instruções, obedecer a suas propostas, seguir suas orientações, receberá, como galardão, seu objeto amado.

Da mesma maneira, em uma relação interdiscursiva, o Kama Sutra faz tais convites, orientações, sugestões e coloca-se como o livro da sabedoria que conduzirá ao amor. É oportuno destacar que o interdiscurso se refere a um agrupamento de unidades discursivas que mantêm uma relação explícita ou implícita com um discurso particular. Segundo Charaudeau e Maingueneau (2004a), para existir a interdiscursividade é necessário que as unidades discursivas pertençam a discursos anteriores do mesmo gênero ou, se contemporâneos, de outros gêneros. Alguns enunciados demonstram isso:

Quaisquer que sejam as carícias feitas por um dos amantes no outro, o mesmo deve ser feito em retribuição, ou seja, se a mulher beijar o homem, ele deve beijá-la, se ela golpeá-lo, ele deve também golpeá-la em retribuição. (p. 71).

Em matéria de amor, o homem deve praticar aquilo que for agradável às mulheres de diferentes origens (...) entre as práticas mencionadas, ou

\footnotetext{
${ }^{4}$ Cf.: Kama Sutra, páginas 121- 123; 160- 164; e outras.

${ }^{5}$ Segundo os estoicos - movimento filosófico dominante no Império Romano, principalmente do século 2 a.C até o século 2 d.C - a paixão amorosa aparece como algo temível e o amor é visto como uma despossessão. Para Veyne (1985), os estoicos eram os educadores da aristocracia e pregadores populares e difundiam uma doutrina contra a paixão e os excessos do desejo. Assim, a obra de Ovídio aparece como uma arte do "fingimento amoroso", uma vez que ensina como o sujeito deve disfarçar-se diante do objeto amado e, desse modo, permanece senhor de si; assim um homem não correria o risco de se despossuir em função de uma mulher ou de um escravo, sexualmente falando.
} 
seja, abraços, beijos etc., as que aumentam a paixão devem ser praticadas primeiro e as que destinam apenas ao divertimento ou à variedade devem ser praticadas depois. (p. 78- 9).

A pessoa criativa deve multiplicar os tipos de união imitando os hábitos de distintos animais e pássaros. Esses diferentes tipos de união, praticados de acordo com os costumes de cada país e com as preferências de cada indivíduo geram amor, amizade e respeito no coração das mulheres. (p. 85).

Assim, Ovídio refere-se, ao lado do Kama Sutra, a uma obra que possui uma visada de incitação $o^{6}$ explícita e por isso pode ser colocado na categoria de manual. De acordo com Charaudeau (2004, p. 23), uma visada corresponde a "uma intencionalidade psico-sócio-discursiva que determina a expectativa (enjeu) do ato de linguagem do sujeito falante e, por conseguinte da própria troca linguageira". Isso implica que a visada se encontra do lado da instância de produção em função de uma construção idealizada que o sujeito comunicante faz de seu destinatário. No entanto, ela deverá ser reconhecida pela instância de recepção e assim propiciar a interação verbal. De modo mais específico, a obra investigada inscreve-se, pois, em uma visada de incitação, pois "eu quer 'mandar fazer' (...), mas, não estando em posição de autoridade, como no caso da prescrição, não pode senão incitar a fazer; ele deve, então, 'fazer acreditar' (...) ao tu que ele será beneficiário de seu próprio ato"... (CHARAUDEAU, 2004, p. 23). Para tanto, o eu utilizará de sedução ou persuasão a fim de que o $t u$ acredite que sua ação retornará em seu próprio bem. Embora seja uma visada dominante, o livro ainda apresenta uma visada de demonstração, em que $e u$ se propõe a estabelecer a verdade através de provas, a partir de uma posição de autoridade de saber, como cientista, especialista, iluminado, como faz Ovídio ao apresentar-se como o Arauto do amor, como aquele que recebe da própria Vênus as orientações para escrever sua arte.

As visadas são selecionadas pelas restrições impostas no e pelo contrato de comunicação. Assim, cada situação de comunicação engendrará uma ou mais visadas. Nesse sentido, o discurso literário pode convocar uma visada de instrução - quando escrito por uma autoridade religiosa, por exemplo -, de incitação - como são os casos analisados -, de demonstração - quando os especialistas são convocados ou quando os autores constroem um Ethos de expert -, ou ainda de informação, quando se quer esclarecer ou informar. Como se vê, uma situação de comunicação pode convocar várias visadas.

Nos três livros que compõem A Arte, parece que Ovídio reconcilia os dois sexos e dá à mulher participação e iniciativa neste jogo sério e leviano que é a conquista amorosa. Em sua estrutura, há o primeiro livro que trata do modo como os homens podem conquistar a mulher amada e lhes transmite os ensinamentos mais eficazes na arte de seduzir. Assim, esse livro ensina aos homens como se dirigir às mulheres, quais as palavras adequadas para o galanteio e ainda os artifícios mais convincentes, como, por exemplo, o uso da promessa e o fingir:

\footnotetext{
6 Na verdade, o que denominamos no trabalho de Literatura Prescritiva refere-se também ao que Charaudeau (2004, p. 23) denomina de Visada de incitação, uma vez que uma obra literária não possui um poder estatutário que determinará a ação do leitor. Uma visada de prescrição implica em uma posição de autoridade que garanta ao enunciador a possibilidade de ordenar: cabe ao interlocutor a obediência. Assim, uma medida provisória presidencial possui um caráter de prescrição, pois o presidente da República possui uma autoridade institucional que o garanta o poder de mando e à população o dever de obedecer.
} 
Tens de agir como apaixonado, e tuas palavras devem dar a sensação de que estás perdido de amor; lança mão de todos os meios para persuadi-la. E como toda mulher se julga digna de ser amada, ser-te-á fácil ser acreditado; e mesmo que seja feia, valoriza a própria beleza (p. 47).

Ou seja: o autor coloca a mulher no lugar de "caça" e revela onde ela poderá ser alcançada; assim, o amor, ou mesmo uma diversão, poderá surgir.

O segundo livro diz respeito à manutenção do amor, ou seja, o que fazer para em como manter o objeto conquistado, enquanto que o terceiro livro é direcionado às mulheres que desejam conquistar seu amado. De modo mais específico, o último livro ensina como as mulheres conquistadas podem agradar aos homens, através de "estratégias de fingimento", cuidados com a beleza e higiene, disfarce dos defeitos contrários aos ideais de beleza romanos, como usar a voz e o olhar para seduzir e, ainda, em como obter relações extraconjugais sem ser descoberta. Finalmente, Ovídio ensina posições sexuais que se adequam melhor à estatura da mulher e também posições que contribuirão para um melhor alcance do orgasmo:

Que a mulher sinta o prazer de Vênus abatê-la até o mais profundo do seu ser, e que o gozo seja igual para ela e para o seu amante. Que não se calem nunca as palavras de carinho e os doces murmúrios, entremeados de palavras lascivas. Desventurada a mulher cujo órgão que deveria proporcionar prazer para ela e para o homem - permanece insensível! (p. 108).

Àquela que foi negado o "prazer do amor" o poeta orienta: finja!

Tens de agir como apaixonado, e tuas palavras devem dar a sensação de que estás perdido de amor; lança mão de todos os meios para persuadi-la. E como toda mulher se julga digna de ser amada, ser-te-á fácil ser acreditado... (p. 47);

Lágrimas também são úteis; com elas amaciarás até o diamante. Cuide para que a tua amada veja o pranto no teu rosto. Se as lágrimas te faltarem (porque nem sempre obedecem à nossa vontade), molha os olhos com as mãos. (p. 48);

$\mathrm{Se}$, porém, queres conservar o amor da tua amiga, faze-a acreditar que estás maravilhado com sua beleza (p. 64);

Desse modo, o que se verifica é o intento de Ovídio em ensinar sua Ars amatoria e transformá-la em uma poderosa ferramenta para conquistar o objeto amado. De modo, talvez para alguns leitores, despudorado, seu ensino centra-se na lógica da conquista, ainda que para isso o conquistador se utilize de estratégias de simulação e de serviço militar. Conforme destaca Duque (2016), em Ovídio os amantes são postos na categoria de soldados do exército, obedecendo, porém, ao general Cupido. Nota-se, de fato, uma série de aproximações entre o ofício do amante e o do militar: ambos são exclusivos dos jovens; no exercício de suas atividades dormem pouco; enfrentam, eventualmente, longos deslocamentos; as duas atividades, por vezes, exigem vigília à porta e a separação pela distância. Ademais, verifica-se o uso lexical bélico-militar: as insígnias, o acampamento militar e as armas utilizadas para ferir os inimigos, além das flechas afiadas. 
É certo que as visadas descritas acima são capazes de construir um ethos do enunciador que aqui, conforme estamos tentando demonstrar, é daquele conquistador que conhece bem as táticas e estratégias de conquista.

\section{VISADAS DISCURSIVAS E ETHOS}

$\mathrm{Na}$ arte retórica, as provas de persuasão são modos de fazer-valer um determinado discurso, pelo domínio da palavra, cabendo ao sujeito falante a propriedade em certas provas retóricas que se assentam, ora em determinados aspectos do caráter ou da moral do orador, ora na disposição do ouvinte, ora no próprio discurso. Conforme destaca Aristóteles, essas provas, também chamadas de provas de persuasão são de três espécies:

[...] umas residem no caráter moral do orador [ethos]; outras, no modo como se dispõe o ouvinte [pathos]; e outras, no próprio discurso, pelo que este demonstra ou parece demonstrar [logos]. Persuade-se pelo caráter quando o discurso é proferido de tal maneira que deixa a impressão de o orador ser digno de fé. [...] Persuade-se pela disposição dos ouvintes, quando estes são levados a sentir emoção por meio do discurso, pois os juízos que emitimos variam conforme sentimos tristeza ou alegria, amor ou ódio. [...] Persuadimos, enfim, pelo discurso, quando mostramos a verdade ou o que parece verdade, a partir do que é persuasivo em cada caso particular (ARISTÓTELES, 1979, p. 49- 50).

Nessa perspectiva, os três campos produzem efeitos no que tange à adesão do auditório, mas a prova éthica associa-se ao fazer-crer tendo em vista que o peso recai sobre a imagem construída do orador sobre seu auditório. De acordo com Maingueneau (2008), a construção de uma imagem do sujeito falante vem, de alguma forma, como uma resposta à demanda por reconhecimento pelo outro como uma pessoa digna de ser ouvida, em função de diversas situações. O ethos de pessoa credível, ou de pessoa confiável, ou de pessoa carismática poderá favorecer a dimensão identificatória, mas, sobretudo, exigirá do sujeito falante a construção para si mesmo de uma imagem que tenha um certo poder de atração sobre seu ouvinte.

A nosso ver, para alcançar seu objetivo Ovídio constrói um Ethos Discursivo baseado em suas experiências amorosas, pois confessa ter amado todas as mulheres: "as altas ou baixas, louras ou morenas, esbeltas ou opulentas, instruídas ou ignorantes, contanto que fossem belas e não tivessem ultrapassado o sétimo lustro de vida" (p. 35). Além disso, o escritor apresenta-se como aquele que recebeu diretamente de Vênus ou de Cupido a incumbência de ensinar aos homens a "arte de amar". Ovídio é, assim, o magister do amor e ele mesmo se apresenta como "O preceptor do amor". Preceptor do amor é aquilo que dá o tom e cria o "estilo" em Ovídio e faz com que seu Ethos seja elaborado com base em um material linguístico próprio e ainda de seu ambiente. Para efeitos de esclarecimento do que se apresenta aqui, em Aristóteles o Ethos é a prova retórica mais convincente e localiza-se no caráter moral do orador. Trata-se da obtenção da persuasão em razão do caráter do orador. No entanto, tal prova deve ser pensada em relação às outras duas - logos e pathos -, uma vez que o efeito visado do discurso é 
construído pelos traços morais do orador, mas também certa disposição do auditório pelo tema. Este deve colocar os sujeitos em situação de serem convencidos pelo orador, ainda que seus atributos morais não sejam tão destacáveis. De semelhante modo, a estruturação textual também pode independentemente do Ethos, convencer o auditório. Tomemos como exemplo o caso de Anna O., paciente tardia de Freud (1889) no Hospital de Salpêtrière. Portadora de um quadro de histeria, não conhecia Freud - que era apenas um estagiário à época - mas tão cedo se deixou influenciar por sua prática de tratamento hipnótico. Em sua estrutura histérica, o mais importante, na verdade, era a sua predisposição em deixar-se ser hipnotizada, o que não dependia do “orador"/hipnotizador/terapeuta, mas do próprio paciente, no caso.

Auchlin (2001) sustenta que o material linguístico e o material ambiental devem ser capazes de ativar os eixos afetivos do interesse, da admiração e da confiança a fim de que seja ativado no interlocutor o efeito de Ethos esperado. É em função do caráter imaginário que o Ethos carrega é que o interlocutor dará crédito ou não ao locutor. Sendo assim, cabe ao sujeito-comunicante a criação e o estabelecimento de um Ethos que acionará no sujeito-interpretante as disposições afetivas que ele experimentará. Assim, ser o preceptor do amor, ser aquele que recebeu diretamente de Vênus a mestria do jovem amor e ainda ser o piloto que conduz o navio em que o amor navega são tentativas linguístico-discursivas empreitadas por Ovídio para acionar no seu interlocutor efeitos de credibilidade. Ovídio "comanda" o amor, ele o obedece e o poeta sabe vingar-se do amor quando este o agita; ele tem a ajuda na proclamação da verdade vinda da própria mãe do amor; enfim, ele e é aquele que sabe das artimanhas do amor, possui modos de ensiná-lo e também de curar aquele que dele padece.

Se o Ethos prévio ${ }^{7}$ de Ovídio faz com que ele seja "escutado", o Ethos discursivo é aquele que garante boa impressão em seu público e pouco importa seu grau de sinceridade. Assim, a garantia argumentativa que o Ethos promove refere-se àquilo que o poeta apresenta e com isso ele elabora um modo de ser tomado a sério e de se engajar na escolha dos argumentos e palavras. Com isso, ele garante, segundo Charaudeau (1992) a credibilidade de seu discurso. São as nomeações que Ovídio se faz, suas experiências no campo do amor e a construção didática de sua obra é que são capazes de inspirar confiança. Alguns enunciados são ilustrativos disso:

A mim Vênus confiou a mestria do jovem amor; serei pois nomeado de Tífis e Automedonte do Amor (p. 23);

Do mesmo modo, o amor me obedece, ainda que transpasse meu coração com suas setas e agite suas tochas. E quanto mais cruelmente me transpasse e me abrase, mais saberei vingar-me das feridas que me causou (p. 24);

"A sorte pode entrar na conquista, mas a conservação é obra de minha arte" (p. 54);

"Cheguei ao fim do meu trabalho; concedei-me a palma, juventude agradecida (...) Automedonte na condução dos carros, assim sou eu como mestre do amor" (p. 78).

\footnotetext{
${ }^{7} \mathrm{O}$ Ethos prévio refere-se aos aspectos encontrados na vida do Orador. Em Ovídio, por exemplo, tal ethos está em sua formação intelectual, em seu círculo de amizades, em sua reconhecida capacidade oratória, em sua obra literária...
} 
A Arte de amar, assim, trata de uma doutrina sobre a técnica amorosa e pode ser aprendida. Dessa maneira, o poeta ensina desde o modo como o apaixonado deve cuidar da aparência até os jogos que ele deve empreender para deixar a amante à sua inteira disposição. É oportuno destacar que a técnica repassada pelo poeta se assenta num saber associado a um saber-fazer através dos quais o sujeito falante, estrategicamente, constrói uma imagem de si, de tal forma que ele se torna credível aos olhos de seu auditório, ao mesmo tempo em que ele se torna atrativo, promovendo o ethos de identificação ${ }^{8}$.

Curiosamente, com quase 50 anos de idade, Ovídio, por razões nunca esclarecidas, foi exilado por Augusto. Uma das hipóteses de seu exílio refere-se aos efeitos causados por sua obra. A celebração do amor extraconjugal pode ter sido tomada como uma afronta intolerável a um regime que promovia determinados valores familiares patriarcais preconizados pelo Império Romano, pois no poeta, embora ainda tenha o homem como foco e referencial em torno do qual tudo se desenvolve, percebe-se, como sustenta NoëlRobert (1995), uma mulher diferenciada de outros autores latinos do período. A mulher não mais é vista apenas como um receptáculo de esperma ou como um meio de satisfação masculina, mas torna-se também, ainda que parcialmente, um sujeito desejante e partilha o prazer com o homem. Enfim, "Ovídio nos apresenta o ato de amor como uma comunhão de dois corpos tentando se dar prazer" (NOËL-ROBERT, 1995, p. 220).

\section{UM BREVE PERCURSO PELO ETHOS CONTEMPORÂNEO}

A contemporaneidade, por sua característica heterogênea, possui diversas visadas acerca do amor em suas produções, sejam elas literárias ou midiáticas. Há visadas de incitação, de prescrição, de instrução, de informação, dentre outras, como as visadas híbridas, por exemplo. Desse modo, pode-se dizer que o ethos amoroso contemporâneo também é um ethos híbrido, mas que, de modo resumido, baseia-se numa visada do saberser feliz. De modo geral, nota-se que a busca por relacionamentos amorosos está atrelada ao fato de que, com eles, as pessoas seriam mais felizes. Nas mais diversas emissões midiáticas, à título de ilustração, verifica-se a constante busca pela felicidade, sobretudo a baseada no amor.

Do ponto de vista das questões associadas ao amor na contemporaneidade, outras questões associadas ao ethos surgem, tendo em vista que diversos fenômenos aí interagem, tais como: os índices sobre os quais se apoia o intérprete vão desde os múltiplos posicionamentos sociais, políticos e econômicos sobre os quais ele orienta sua vida, passando por elementos de ordem subjetiva e sexual. Em razão disso, o ethos se elabora por meio de uma percepção complexa, mobilizadora da afetividade do intérprete, que extrai suas informações tanto dos elementos textuais materiais dos textos literários e midiáticos quanto do ambiente. Tais elementos eram constituintes das visadas presentes na obra de Ovídio e permanecem ainda hoje, de maneira diferenciada, amplificada pelo universo midiático, com a possibilidade de espaços virtuais de circulação para a obtenção

\footnotetext{
${ }^{8}$ Não entraremos na discussão da relação entre o ethos de identificação e o pathos em função de não ser este o propósito de nosso ensaio. Todavia, em diversos discursos, mas talvez mais marcadamente no discurso político, $\mathrm{O}$ ethos de identificação coloca o problema da fronteira com os efeitos do pathos, já que este busca tocar o afeto do cidadão.
} 
da conquista amorosa, fato que, por razões óbvias, não estavam presentes na obra ovidiana.

O ethos do amor na contemporaneidade não pode ser dissociado das condições de produção de uma dada sociedade que, no Ocidente, é predominantemente capitalista. Assim, os investimentos amorosos seguem a lógica dos investimentos do capital e dos bens de consumo. Os sujeitos parecem apresentar, nas relações amorosas, a mesma lógica consumista referente a qualquer objeto de satisfação. Segundo Zigmunt Bauman (2003), as escolhas amorosas obedecem à lógica da sociedade de consumo, pautada na fruição prazerosa individual. Para esse autor:

Automóveis, computadores ou telefones celulares perfeitamente usáveis, em bom estado e em condições de funcionamento satisfatório são considerados, sem remorso, como um monte de lixo no instante em que novas e aperfeiçoadas versões aparecem nas lojas e se tornam o assunto do momento. Alguma razão para que as parcerias sejam consideradas uma exceção à regra? (BAUMAN, 2003, p. 28)

As "novas e aperfeiçoadas versões" seriam aplicadas à dimensão amorosa? Como se pode ver, Bauman (2003) estabelece uma associação entre o consumo de mercadorias e as escolhas amorosas, estando os objetos de amor destinados a um prazo de validade estipulado pelas leis do mercado da libido.

Todavia, é oportuno destacar que no ethos contemporâneo do amor o paradoxo é uma marca. De um lado existe a multiplicidade, brevidade e fluidez dos laços amorosos atuais possibilitados pela conectividade e pela tecnologia. Com os diversos aplicativos de encontros amorosos e sexuais, o amor está na palma da mão, o que possibilita a dimensão de multiplicidade. Por outro, verifica-se no discurso dos jovens, mesmo em redes sociais e aplicativos, a demanda por um amor que garanta a complementariedade entre os sexos. Enquanto algumas se precipitam nas experiências corpo a corpo, de forma intensa e fugaz, outras escrevem sobre o amor eterno; ou ainda encontramos aquelas pessoas que associam a busca pelo amor eterno à multiplicidade de experiências, em uma espécie de tentativa de alcançar no múltiplo, o um.

Desse modo, podemos sustentar que o paradoxal ethos contemporâneo do amor, sobretudo os veiculados pela internet, apontam tanto para a importância do amor durável e complementar tanto quanto para descartabilidade das parcerias amorosas. Todavia, a lógica militar da conquista, aquele presente em Ovídio, ainda permanece em certas produções midiáticas contemporâneas, como as revistas masculinas e femininas, à título de ilustração, estando presente tanto no recorrente uso da linguagem de cunho militar conquistar, dominar, estratégias, cerco, dentre tantas outras - quanto nas apropriações discursivas de estrategistas militares (A arte da guerra, por exemplo) aplicadas ao campo sexual-amoroso.

\section{CONSIDERAÇÕES FINAIS}

Este ensaio teve por objetivo mostrar a interlocução que existe entre um certo tipo de literatura que podemos chamar de "literatura de iniciação amorosa-sexual" aqui representada por um fragmento da obra de Ovídio e sua apropriação/presença pelos/nos 
discursos contemporâneos. De algum modo, pode-se perceber que certos temas ligados ao sexo e ao erotismo, ou seja, temas que há muito tempo eram reservados a um universo livresco e a um público restrito, ousam hoje se mostrar no universo midiático, universo amplo e de fácil abordagem, o que pode ser representado por uma das asserções da psicanálise contemporânea: o que durante muito tempo foi dissimulado, ou seja, o objeto erótico, nos dias atuais se revela sem falsos pudores na cena cotidiana das mídias. Além de identificarmos como a arte de amar do escritor latino associa-se, de alguma maneira, à arte de fingir, verificamos também que certas representações contemporâneas do homem e da mulher foram construídas por influência desses "manuais" ou, em outros termos: a obra de Ovídio, assim como outros contemporâneos seus, foram substituídos nos dias de hoje pelo discurso veiculado por um certo tipo de mídia, ou seja, aquele que oferece aos seus espectadores "receitas" de amor, modelos de comportamento amoroso e estratégias (ligadas a procedimentos de pathemização) para tornar este sentimento algo fácil de ser obtido.

Conforme dito anteriormente, o discurso amoroso constitui-se como um dos motores do universo de ficção, inspirando novelas ou séries de televisão, filmes, romances, revistas e todo um conjunto de produtos provenientes da cultura de massas e da indústria cultural e, de acordo com as discussões de Charaudeau (2004), em torno das visadas discursivas, os gêneros que integram os discursos supracitados possuem um objetivo pedagógico. Assistimos, assim, a "intrusão" de um assunto que anteriormente era reservado ao universo dos livros (que poucos poderiam ler, que não ficavam à vista nas bibliotecas) passar para o universo midiático, sobretudo o das revistas, ou seja, um espaço onde há mais acesso e visibilidade, segundo uma lógica do ethos contemporâneo.

Dessa forma, as estratégias propostas em $A$ arte de amar sustentam-se em visadas pedagógicas criadas para construir a ideia de amor, conquista, masculinidade e feminilidade em sua época e, de certa forma, podem ser transportadas para a contemporaneidade. Se de alguma maneira a obra desse importante escritor latino apresenta orientações no campo da sexualidade masculina e feminina é oportuno também destacar que ao mesmo tempo em que ele "ensina" a partir de uma visada pedagógica, de alguma forma ele configura uma certa representação de homem e mulher (ethos coletivo). Resta-nos pensar, ainda, em que medida uma memória dos discursos se apropria de representações em torno das quais se constroem identidades coletivas sobre as relações entre homens e mulheres e, do mesmo modo, quais as estratégias discursivas são utilizadas para a elaboração de um discurso do "como emocionar o outro".

\section{REFERÊNCIAS}

ARISTÓTELES. Arte Retórica e Arte Poética. Introdução Goffredo Telles Junior. Tradução de Antônio Pinto de Carvalho. Rio de Janeiro: Ediouro - Tecnoprint, 1979.

AUCHLIN, Antoine. Ethos et expérience du discours: quelques remarques. In: M. WAUTHION, Simon (éds). Politesse et idéologie. Rencontres de pragmatique et de rhétorique conversationnelle. Louvain: Peeters, 2001.

BAUMAN, Zigmunt. Comunidade: a busca por segurança no mundo atual. Rio de Janeiro: Jorge Zahar Ed., 2003.

CHARAUDEAU, Patrick. Grammaire du sens et de l'expression. Paris: Hachette, 1992. 
CHARAUDEAU, Patrick. Visadas discursivas, gêneros situacionais e construção textual. In: MACHADO, Ida Lucia; MELLO, Renato de. Gêneros reflexões em análise do discurso. Belo Horizonte, NAD/FALE-UFMG, 2004.

DUQUE, Guilherme Horst. Tu mihi sola places": sobre um caso de alusão. Letras em Revista. Teresina, v. 07, n. 01, jan. /jun. 2016.

FERNANDES, Marcelo Vieira. A Poesia Didática Elegíaca e a Poesia Elegíaca Didática dos Medicamina de Ovídio, e Ovídio, Produtos para a Beleza Feminina: tradução poética. Classica - Revista Brasileira de Estudos Clássicos, [S.1.], v. 25, n. 1/2, p. 259268, jul. 2012. ISSN 2176-6436. Disponível em: $<$ https://revista.classica.org.br/classica/article/view/87> . Acesso em: 01 mar. 2019.

FREUD, Sigmund. Estudos sobre a histeria (1889). Edição standard brasileira das obras completas. Rio de Janeiro: Imago, 1996.

MAINGUENEAU, Dominique. A noção de ethos discursivo. In: MOTTA, A. R.; SALGADO, L. (Orgs.). Ethos discursivo. São Paulo: Contexto, 2008 a. p.11-29.

OVÍDIO [Públio Ovídio Nasão]. A arte de amar. São Paulo: Martin Claret, 2007. Edição original publicada no ano 43 d.C.

ROBERT, Jean-Noël. Os Prazeres em Roma. São Paulo: Martins Fontes, 1995.

Artigo recebido em: mar. de 2020.

Aprovado e revisado em: out. de 2020.

Publicado em: dez. de 2020.

Para citar este texto:

MIRANDA, Cássio Eduardo Soares. A Arte de Amar ... e de Fingir: um ensaio discursivo sobre o amor em Ovídio. Entremeios [Revista de Estudos do Discurso, ISSN 2179-3514, on-line, www.entremeios.inf.br], Seção Estudos, Programa de Pós-Graduação em Ciências da Linguagem (PPGCL), Universidade do Vale do Sapucaí (UNIVÁS), Pouso Alegre (MG), vol. 22, p. 6-16, jul. - dez. 2020.

DOI: $\underline{\text { http://dx.doi.org/10.20337/ISSN2179-3514revistaENTREMEIOSvol22pagina6a16 }}$ 